\title{
NOTAS SOBRE POLOS DE DESARROLLO Y TRANSICIÓN*
}

\author{
JOSÉ LUIS CORAGGIO \\ El Colegio de México
}

\section{Introducción}

LA POSIBILIDAD de que en situaciones de transición social -como la que atraviesa actualmente Nicaragua- - , donde existe la acuciante necesidad de desarrollar mecanismos e ideologías que den sustento a la planificación en desarrollo, se reintroduzcan conceptos cuya eficacia teórico-metodológica haya sido seriamente puesta en duda en los países latinoamericanos en relación al tipo de planificación que puede desarrollar el estado capitalista, hace pensar que puede ser válido reincidir sobre el tema de los denominados "polos de desarrollo".

Las peculiaridades del proceso nicaragüense brindan la oportunidad de interponer la crítica a la posible importación directa y sin mediaciones de conceptos acuñados tanto en los países capitalistas centrales como en los de "planificación centralizada". Esto es así, no tanto por razones académicas, sino porque tales conceptos suelen jugar un rol ordenador de las ideas acerca de la práctica, ordenamiento que, una vez cristalizado, es difícil de someter a una crítica tardía.

El solo hecho de que en un seminario sobre las Estrategias de Desarrollo Agrario en Nicaragua se planteara este tema nos incitó a intentar una aproximación a tal crítica.

\section{La teoria original relativa a los polos de desarrollo ${ }^{1}$}

Muy suscintamente, podemos caracterizar la Teoría de los Polos de Desarrollo, en la versión original de François Perroux, de la si-

* Trabajo presentado al seminario sobre Estrategias del desarrollo Agrario en Nicaragua, realizado en Managua en marzo de 1981.

1 En dos trabajos previos hemos analizado las bases de esta teoría con mayor detalle, aportando también una amplia bibliografía. Ver: José L. Coraggio: "Hacia una revisión de la teoría de los polos de desarrollo" (1972) y "Polarización, desarrollo e integración" (1973), incluidos en Crítica de la planificación regional en América Latina, Ed. Terra Nova, México, 1981. 
guiente manera: en ningún sistema económico el desarrollo se da de manera uniforme y homogénea sino mediante impulsos de innovación cualitativa y cambio cuantitativo concentrados en determinadas ramas de actividad. Tales impulsos desestabilizan el sistema a través de las relaciones tecnológicas y económicas con otras actividades, generando efectos inducidos, principalmente sobre los sectores directamente ligados mediante relaciones de intercambio.

Dichos impulsos no se explican por la naturaleza misma de las actividades sino también por las características organizacionales y por el peso económico de las mismas en una estructura heterogénea, caracterizada por relaciones asimétricas, entre empresas dominantes y empresas dominadas o subordinadas. En una economía capitalista tales características se dan en los conglomerados oligopólicos.

Para Perroux, dicho rol lo continúan cumpliendo incluso ciertos complejos industriales en sistemas como el soviético. Esta visión global del desarrollo económico estaría apoyada por series estadísticas que muestran cómo diversas industrias "de punta" van asumiendo este rol dinamizador del conjunto de la economía mundial. Un aspecto no desarrollado por esta teoría es que los efectos de estos núcleos desestabilizadores no necesariamente son "posinivos" para los sectores subordinados, en tanto se produce un complejo efecto de creación/destrucción de fuerzas productivas e incluso de relaciones sociales. Este es un aspecto secundario para tal teoría en tanto su inoculable objotvo es la "modemización", considerada cono sinónimo de desamolio.

Si bien la teoria no brinda una especificación general del tipo de actividad impulsora, supone en general que será una actividad industrial manufacturera.

En resumen, en la version original de la teoría: los polos de desarrollo son los grandes oligopolios de orden mundial, sean éstos "capitalistas o socialistas"; la polarización es un proceso de desarrollo desigual de las fuerzas productivas donde las alternativas para los sectores subordinados serian: o crecimiento asociado con modernización o destrucción, y la "teoria" de los polos de desarrollo sería una descripción de estos procesos en el sistema industrial mundial.

\section{De la descripción a la "estrategia"}

Las industrias que ejercen estos efectos asimétricos son denominadas por Perroux "industrias motrices". El concepto de motricidad queda definido siempre con respecto a un subconjunto de actividades "arrastradas" por la dinámica del polo. En tal sentido, cabría 
aplicar dicho concepto no sólo a la economía mundial como un todo, sino también a ámbitos más limitados (territorial o sectorialmente). De este modo, actividades que no podrían ser caracterizadas como motrices para el sistema mundial estarían catalogadas como tales para subsistemas menores (nacionales, regionales, etc.). Esta extensión del concepto aparentemente le brinda posibilidades operativas para el diseño de estrategias de desarrollo en ámbitos determinados. Por lo demás, al referir el análisis a procesos relativamente compartimentalizados, la génesis e implantación de los denominados polos de desarrollo puede ser vista como determinada exógenamente a dichos procesos. Simultáneamente cabe incorporar un elemento voluntarista a la teoría, convirtiéndolo, de sistema conceptual descriptivo de los procesos de desarrollo capitalista, en "estrategias para el desarrollo". Se trataría entonces de incorporar polos de desarrollo-cuya dinámica responde a procesos de otro orden- a subsistemas que de por sí no los engendran endógenamente, con la esperanza de que produzcan efectos impulsores respecto a las actividades actuales o potenciales. Si tales implantaciones: a) se integran al subsistema y contribuyen a la puesta en marcha de un proceso dinamizador crecientemente autosostenido, b) o si meramente trasmiten efectos cuantitativos cuya dinámica queda atada a la propia del "polo", o si c) se convierten en enclaves cuyos efectos sobre el subsistema son predominantemente negativos, se convierte ahora en una cuestión central en la discusión de la estrategia.

La respuesta genérica que se puede obtener para esta cuestión es que los resultados obtenidos dependerán de las precondiciones o de los procesos de acompañamiento que puedan existir en el propio subsistema. Cuando se constata que tales condiciones están directamente relacionadas con el grado de desarrollo previamente alcanzado, la estrategia pierde eficacia en tanto tendería a ser apropiada solamente para acelerar el desarrollo en subsistemas ya relativamente desarrollados, pero muy probablemente produciría enclaves con fuertes efectos negativos cuando se aplica en ámbitos atrasados.

\section{Del sistema mundial a la región polarizada}

Cuando el subsistema de arrastre es delimitado como una determinada porción del territorio, donde todo lo allí contenido constituye un conjunto susceptible de ser desarrollado (sin necesariamente constituir un subsistema internamente articulado), se produce una "territorialización del polo". Esto pasa a ser visualizado como un centro urbano cuyas características de tamaño, dinámica económica, 
etc., le permitirían operar como "polo de desarrollo" respecto a su ámbito de influencia inmediata o región polarizada.

Urbanización, industrialización y desarrollo se confunden en esta nueva visión, para la cual los centros menores y las poblaciones rurales pasan a constituir el "subsistema" desestabilizado, arrastrado, modernizado o eventualmente destruido por la dinámica del "polo". Con la intención de evitar esta confusión, algunos autores proponen diferenciar entre polos de desarrollo (actividades motrices) y centros de desarrollo (centros urbanos de crecimiento rápido).

En este trastocamiento del concepto original, la visión del polo como empresa oligopólica de punta da lugar a una visión del polo como aglomeración urbana de actividades. En la primera visión la relación del polo con su subsistema de arrastre era conceptualizada a través del análisis de las relaciones con empresas y actividades subordinadas por relaciones de propiedad directa de activos, por relaciones de crédito, por dependencias tecnológicas, por relaciones de intercambio asimétricas, etc. Asimismo procedía analizar las relaciones de intercambio con los trabajadores y las correlaciones de fuerza en el proceso de determinación de las relaciones de explotación. En esta nueva visión, el polo aparece como aglomeración acoplada a un conjunto de agentes localizados, por medio de flujos físicos de materias primas, productos, fuerza de trabajo, etc. La población trabajadora aparece básicamente como mediadora del efecto inducido de demanda de bienes-salario.

Esta pérdida de riqueza en el análisis de la realidad social se agrava cuando la "región" polarizada es definida apriorísticamente. Así, se determina que cierta zona atrasada debe pasar a ser desarrollada por el crecimiento de cierto centro urbano que se constituirá en "su polo", sin que la articulación entre ambos elementos esté garantizada ni por las estructuras de relaciones existentes ni por los programas propuestos. En general, en este tipo de enfoque, la "región polarizada" pasa a ser considerada como un conjunto internamente homogéneo del cual interesa únicamente el comportamiento de indicadores agregados que registren los posibles efectos multiplicadores del crecimiento del "polo".

\section{Finalmente, la vulgarización del concepto}

En América Latina el término "polo de desarrollo" ha sido difundido a tal punto que aparece en casi cualquier plan de desarrollo regional o en cualquier planteamiento de configuración territorial-objetivo para una sociedad. Aparece incluso en planes de desarrollo intra- 
urbano. Por lo demás, las condiciones para que una actividad opere como motriz en un determinado ámbito territorial han sido reducidas virtualmente a su caracterización como "moderna" (respecto al medio en que va a implantarse) y adicionalmente a que tenga una "masa" tal que efectivamente tenga capacidad para desestabilizar el subsistema. Asimismo, se ha acentuado su carácter urbano, ${ }^{2}$ aunque se ha extendido la gama de actividades para incluir ciertos servicios (turismo, transporte, etc.).

Empíricamente se ha estado comprobando que implantaciones industriales modernas y relativamente masivas en áreas de relativo atraso social no sólo no conducen necesariamente a procesos de difusión del desarrollo económico-social en el ámbito regional inmediato, sino que en muchos casos producen una acentuación del atraso o simplemente la desaparición de las poblaciones y actividades preexistentes. Sin embargo, este hecho no ha producido que los medios académicos y de planificación rechacen la teoría, sino que ésta "resiste" mediante la incorporación de condiciones adicionales. Para quienes enfatizan los aspectos "funcionales", la estrategia funcionará cuando se den condiciones previas de desarrollo de un sistema empresarial, con su correspondiente sistema de información, de una mercantilización de la producción, de una adecuación eficiente del aparato gubernamental, de una complejización y diversificación de la economía regional, etc. Para quienes enfatizan en cambio los aspectos "territoriales", será condición previa la existencia de un sistema urbano integrado, con centros de diverso tamaño conectados por medios de comunicación y transporte eficientes, con una adecuada fluidez de los recursos productivos, etc.

En cualquier caso, estas apreciaciones llevan necesariamente a afirmar que la estrategia de los polos de desarrollo sería eficaz en relación a regiones atrasadas si existiera un plan o un sistema de planes concertados que garantice la construcción simultánea del polo y de sus condiciones de articulación con el medio regional.

La pregunta que cabe hacerse es; ¿cuál es el componente "estratégico" de una propuesta que, estando pensada para un sistema capitalista, requiere una capacidad de planificación social y de asignación directa de recursos de la cual se carece por la misma naturaleza del sistema? Precisamente el posible carácter "estratégico" de la propuesta hubiera residido en determinar en cada caso cuál o cuáles serían las actividades potencialmente motrices para una región, con ca-

2 Así, la introducción de la producción cafetalera en un contexto de economía campesina de subsistencia no sería pensable como un caso de polarización. 
pacidad para multiplicar un efecto primario planificado y poner en marcha un proceso de desarrollo regional autososterido, economizando justamente esa escasa capacidad de planificación social y librando al mercado la concretización de los efectos secundarios. En la versión vulgarizada de la teoría, tal carácter se ha perdido.

\section{Polos de desarrollo y planificación cèntralizada}

Lo expuesto puede inducir a pensar que la eficacia de la estrategia de los polos de desarrollo (como estrategia para la superación del subdesarrollo) es escasa en los países o regiones donde dominan los mecanismos de mercado, mientras que sería alta en países donde se imponen las leyes de la economía planificada.

En la URSS o en Cuba, por ejemplo, existe el concepto de los complejos o combinados territoriales de producción, ${ }^{3}$ en el cual se ha querido ver la concreción efectiva del concepto de polo de desarrollo en un sistema planificador. Pero estos complejos no son otra cosa que conjuntos de actividades vinculados tanto por relaciones de insumo-producción como por el uso común de infraestructura productiva o de consumo colectivo de la población localizada, o por la utilización común de un pool de fuerza de trabajo, etc. Por lo tanto, su característica diferencial es la planificación conjunta de actividades ligadas, con lo cual la eficiencia económica global se incrementa. El número, y escala/ubicación y composición de los diversos comple jos territoriales de producción es establecido en base a esquemas de distribución territorial de las fuerzas productivas definidos a nivel del sistema en su conjunto. Se trata, pues, de un caso de cálculo económico eficiente en una sociedad donde se planifica la creación y asignación de los recursos productivos a partir de objetivos sociales y no de una estrategia de generación inducida de dichos recursos por medio de los mecanismos de mercado regulados por las leyes de acumulación de capitales. La planificación, al considerar simultáneamente un complejo sistema de objetivos y medios, minimiza los efectos inducidos, librados a mecanismos con leyes exógenas al plan mismo. Por lo tanto, difícilmente podría homologarse polos de desarrollo con combinados territoriales de producción en base a la característica común de tratarse de concentraciones territoriales de fuerzas productivas.

3 Ver: Esperanza Castellanos: "Complejos territoriales productivos. El Norte de Oriente", IX Conferencia de Científicos Regionalistas de los países miembros del CAME, La Habana, octubre 1979 . 


\section{La posible relevancia de la estrategia de los polos de desarrollo} en situaciones de transición

En base a las apreciaciones anteriores cabe ahora enfocar la cuestión planteada como tema de este escrito: ¿cuál es la eficacia posible de una estrategia de desarrollo regional por la vía de polos de desarrollo en una situación caracterizada como de transición? Hemos planteado que tal "estrategia" ha resultado del trastocamiento de un concepto originalmente pensado para describir los proceso de desarrollo desigual que caracterizan al capitalismo y que, en tanto propuesta orientadora del diseño de estrategias de desarrollo de regiones atrasadas, tiene un largo historial de fracasos en los países latinoamericanos. En parte dicho resultado se debe a una incorrecta concepción de los fenómenos de la polarización capitalista y a la correspondiente evaluación de las posibilidades de canalizarlos por medio de la acción estatal. En parte, a la imposibilidad estructural del tipo de planificación que tal vía de desarrollo exigiría. Pero por otro lado hemos encontrado que en las economías de planificación centralizada no procedería aplicar esta "estrategia", en tanto la organización territorial de las fuerzas productivas, de las condiciones de vida de la población, etc., no están libradas a mecanismos de inducción importantes como los que la misma supone. Surge entonces la cuestión: ¿en las economías de transición, donde coexisten un sector privado importante con un área creciente de propiedad del pueblo y donde subsisten e incluso se desarrollan los mecanismos mercantiles de organización de la producción y distribución junto con una creciente actividad social de planificación, no será posible retomar esta propuesta del desarrollo por la vía de "polos" encontrando la combinación adecuada entre mecanismos de inducción y planes sociales?

Adicionalmente, si la respuesta fuera positiva, cabría preguntarse en qué términos concretos podria plantearse tal estrategia. Aquí nos limitaremos a exponer lo que creemos serían algunos resultados de una investigación para dar cuenta de la cuestión planteada.

\section{Algunas cuestiones relativas al diseño de un modelo de desarrollo regional}

Cualquier intento de diseño de una estrategia de desarrollo regional debe partir de la negación del economicismo y el tecnologicismo imperantes en la mayoría de quienes propugnan la concepción de los polos de desarrollo. El proceso de desarrollo de una región atrasada debe verse como un complejo de determinaciones no sólo económicas y tecnológicas sino también políticas, sociales e ideológicas. 
La "región" no será visualizada como un conjunto de "actividades", sino como un subsistema social donde la determinación de los diversos sectores sociales y sus contradicciones es central. Más aún, el análisis debe superar el nivel de los "roles" puros (el campesino, el comerciante, el obrero, el banquero, etc.), identificando los personajes sociales que suelen ser una variable y compleja superposición de funciones. El problema de las formas de articulación de los diversos grupos sociales en base a su diversa inserción en el sistema productivo pasa a jugar un papel central en el análisis y en el diseño de la estrategia, pues ésta tendrá que ver no sólo con la posible introducción de nuevos recursos productivos y/o de nuevas líneas de producción sino principalmente con la reestructuración de dichas articulaciones. Desarrollar una sociedad o un determinado segmento de la sociedad implica reorganizarla internamente y redefinir su vinculación con el todo social en el cual se inserta. En un proceso de transición, donde las relaciones interpersonales directamente sociales tienen un peso creciente y donde lo económico tiende a subordinarse a lo político, estas rearticulaciones no pueden quedar totalmente libradas a mecanismos de inducción, sino que deben también ser objetivo consciente de la acción social.

Sin embargo, proponer una estrategia que considere en un pie de igualdad todas y cada una de las relaciones involucradas sería justamente negar su carácter estratégico, que resulta de la priorización, de la selectividad de las relaciones fundamentales. Partimos de la sostenida importancia de los procesos económicos en la organización de la vida social en una etapa de transición y simultáneamente aceptamos que en general, en toda formación social existe “. . .una determinada producción que asigna a todas las otras su correspondiente rango e influencia, una producción cuyas relaciones asignan a todas las otras el rango y la influencia". 4 En consecuencia, una estrategia de desarrollo para un subconjunto regional puede y debe concentrarse en el desarrollo a partir de una base económica que tenga esas características dominantes. La definición de dicha producción no puede hacerse exclusivamente en términos del tipo de proceso de trabajo o del tipo de productos que obtiene (minería, agricultura, industria, etc.) sino también en términos del tipo de forma de organización social predominante (agricultura mercantil, de autosubsistencia; industria artesanal o fabril, etc.). Desde esta perspectiva podría decirse que se rescata la idea de la teoría original de los polos de de-

4 Karl Marx, Introducción General a la Crítica de la Economía Política (1857), Cuadernos de Pasado y Presente No. 1. 
sarrollo de que existen, en toda estructura productiva, actividades dominantes y actividades subordinadas y que las primeras proveen la fuerza motriz al conjunto. Sin embargo, en esta propuesta amplia que hacemos han desaparecido el sesgo "industrialista" e incluso el "urbanista" que caracterizan los enfoques previamente discutidos. Muy bien puede ser la producción agrícola la que ocupe el lugar central en el diseño de una estrategia dinamizadora de un ámbito regional dado, provisto que no se desvincule producción, circulación y distribución en el análisis. En este caso los asentamientos urbanos aparecerán más como centros de apoyo a la actividad agrícola y de articulación con el sistema en su conjunto que como "polos". El desarrollo de agroindustrias puede, sin embargo modificar esta relación, y desde esta nueva actividad reorganizarse la actividad agrícola en múltiples sentidos, pasando ahora a subordinarse a la primera.

Lo dicho permite afirmar que no hay un modelo único de desarrollo regional que sustituya al propuesto por la teoría de los polos de desarrollo, sino que debe establecerse en cada caso, a partir de principios muy generales, cuál sería la mejor vía para el diseño de una estrategia. Esto es así no sólo porque las diversas regiones tienen bases de recursos naturales y humanos diversos, porque tienen una diversa historia productiva y cultural en general, etc., sino también porque la combinación y formas sociales de producción (área de propiedad del pueblo, propiedad privada, propiedad comunal, etc.) varían entre ellas, como también variará la correlación de fuerzas existentes, por más que estén sobredeterminadas por la correlación a nivel nacional.

Dos consideraciones adicionales: la búsqueda de estrategias de desarrollo regional que rompan con las tendencias heredadas de desarrollo desigual debe integrarse en un marco nacional de organización territorial de las fuerzas productivas, que establezca las tendencias deseadas de una nueva división interregional del trabajo. Por otro lado, las regiones no son entes preexistentes siempre - ya- dados, sino que justamente se trata de construir una regionalización objetiva de los procesos sociales que sea eficaz política y económicamente. 